\title{
A Comparative Analysis of Antimicrobial and Antioxidant Activity between Green Tea, Green Coffee, Pine Apple and Lemon Juice
}

\author{
Jagriti Singh ${ }^{1}$, Satyam Khanna ${ }^{2}$, Vinay Dwivedi ${ }^{1}$, Srinath Pandey ${ }^{1}$, \\ Prashant Ankur Jain ${ }^{3}$ and Ved Kumar Mishra ${ }^{*}$
}

${ }^{1}$ Department of Biotechnology, Naraina Vidya Peeth Engineering and Management Institute, Gangaganj, Panki, Kanpur, Uttar Pradesh-208020, India

${ }^{2}$ RASS Biosolutions Pvt. Ltd., 16/19F, Civil Line, Kanpur, Uttar Pradesh-20800, India

${ }^{3}$ Department of Computational Biology and Bioinformatics (CBBI), Jacob Institute of

Biotechnology and Bioengineering (JIBB), Sam Higginbottom University of Agriculture

Technology and Sciences (SHUATS), Allahabad, Uttar Pradesh-211007, India

${ }^{4}$ Vidhyashram Educational and Development Hub (VED Hub), 204, Dih-Ganjari, Gangapur, Varanasi, Uttar Pradesh-221302, India

*Corresponding author

\section{A B S T R A C T}

Keywords

Antioxidant,

Antimicrobial

activity, IBS,

DPPH, Kirby-

Bauer test etc

Article Info

Accepted:

12 October 2019

Available Online:

10 November 2019
A comparative study of antimicrobial and antioxidant activity between Green Coffee, Green tea, Lemon \& Pine apple. Here we study about the antimicrobial effect we know that green tea, green coffee, lemon pine apple, etc. That is essential for our daily life however insignificant person recognize the accurate explanation which is behind of these. It contains some unique properties which are known as the Antimicrobial Effect to fight against the pathogen simultaneously, so how it is works which is describe as follows- So we evaluated extract of these sample for pilot scale testing and we test with respect to a (Escherichia coli) bacteria, which is a gram-negative, Rod shaped bacteria. And these tests are known as Disk diffusion method. Now in case of Antioxidant effect we test the free radical searching action of each and every one the extracts and that are evaluated by DPPH(1,1-diphenyl 1-2 picryl-hydrazyl) method.

\section{Introduction}

Antimicrobial activity refers to the method of assassination or reduces the infection causing microbes. Various antimicrobial causes are intended for this function. Antimicrobial possibly is anti-fungal, anti-bacterial, or else antiviral. They each and every one has dissimilar modes of action by which they act to suppress the infection. A greater attention 
has been paid to antimicrobial activity screening and evaluating methods. Several bioassays such as disk-diffusion, well diffusion and broth or agar dilution are well known and commonly used, but others such as flow cytofluorometric along with bioluminescent methods are not widely used because they require specified equipment along with further evaluation for reproducibility along with standardization, even if they can provide rapid results of the antimicrobial agent's effects along with as well as a better understanding of their impact on the viability along with as well as cell damage inflicted to the tested microorganism. A substance that inhibits oxidation, especially one used to counteract the deterioration of stored food products a substance such as vitamin $\mathrm{C}$ or $\mathrm{E}$ that removes potentially damaging oxidizing agents in a living organism.

\section{Antioxidants}

Antioxidants are compounds that inhibit the oxidation. Oxidation is a chemical reaction that can produce free radicals, thereby leading to chain reactions that may damage the cells of organisms. Antioxidants such as thiols or ascorbic acid (vitamin C) terminate these chain reactions. To balance the oxidative state, plants along with as well as animals maintain complex systems of overlapping antioxidants, such as glutathione along with as well as enzymes (e.g., catalyse along with superoxide dismutase), produced internally, or the dietary antioxidants vitamin $\mathrm{A}$, vitamin $\mathrm{C}$, as well as vitamin E.

The term "antioxidant" is mostly used for two entirely different groups of substances: industrial chemicals that are added to products to prevent oxidation, as well as naturally occurring compounds that are present in foods as well as tissue. The former, industrial antioxidants have diverse uses: acting as preservatives in food as well as cosmetics, along with as well as being oxidationinhibitors in fuels.

Importantly, antioxidant dietary supplements have not yet been shown to improve health in humans, or to be effective at preventing disease. Supplements of beta-carotene, vitamin A, along with as well as vitamin $\mathrm{E}$ have no effect on mortality rate or cancer risk. Additionally, supplementation with selenium or vitamin $\mathrm{E}$ do not reduce the risk of cardiovascular disease Antioxidant takes a important role in such products like- (Green coffee, Green tea/Normal tea, Lemon, pine apple etc.)

\section{Green coffee beans}

Overview Information "Green coffee" beans are coffee seeds (beans) of Coffee a fruits that have not yet been roasted. The roasting process of coffee beans reduces amounts of the chemical chlorogenic acid. Therefore, green coffee beans have a higher level of chlorogenic acid compared to regular, roasted coffee beans. Chlorogenic acid in green coffee is thought to have health benefits.

Green coffee became popular for weight loss after it was mentioned on the Dr. Oz show in 2012. The Dr. Oz show referred to it as "The green coffee bean that burns fat fast" along with as well as claims that no exercise or diet is needed.

People take green coffee by mouth for obesity, diabetes, high blood pressure, Alzheimer's disease, along with as well as bacterial infections.

\section{How does it work?}

Green coffee beans are coffee beans that have not yet been roasted. These coffee beans contain a higher amount of the chemical chlorogenic 
acid. This chemical is thought to have health benefits. For high blood pressure it might affect blood vessels so that blood pressure is reduced. For weight loss, chlorogenic acid in green coffee is thought to affect how the body handles blood sugar along with as well as metabolism.

\section{Uses and effectiveness}

Insufficient evidence for High blood pressure: Early research suggests that taking green coffee extracts containing $50 \mathrm{mg}$ to $140 \mathrm{mg}$ of chlorogenic acids daily for 4 weeks to 12 weeks can reduce blood pressure in Japanese adults with mild along with as well as untreated high blood pressure. Systolic blood pressure (the top number) appears to be reduced by $5 \mathrm{mmHg}$ to $10 \mathrm{mmHg}$. Diastolic blood pressure (the bottom number) appears to be reduced by $3 \mathrm{mmHg}$ to $7 \mathrm{mmHg}$.

\section{Obesity}

Early research shows that adults with obesity who take a specific green coffee extract (Svetol, Naturex) five times daily for 8 weeks to 12 weeks, either alone or together with the regular coffee product Coffee Slender (MedEq Ltd., Tonsberg, Norway), lose an average of 2.5 to $3.7 \mathrm{~kg}$ more weight than people taking a placebo or regular coffee by itself.

\section{Alzheimer's disease.}

Type 2 diabetes.

Other conditions.

More evidence is needed to rate green coffee for these uses.

\section{Side effect along with as well as safety}

Green coffee is possibly safe when taken by mouth appropriately. Green coffee extracts taken in doses up to $480 \mathrm{mg}$ daily have been used safely for up to 12 weeks. Also, a specific green coffee extract (Svetol, Naturex, South Hackensack, NJ) has been used safely in doses up to $200 \mathrm{mg}$ five times daily for up to 12 weeks. It is important to understand that green coffee contains caffeine, similar to regular coffee.

Therefore, green coffee can cause caffeinerelated side effects similar to coffee. Caffeine can cause insomnia, nervousness along with as well as restlessness, stomach upset, nausea along with as well as vomiting, increased heart along with as well as breathing rate, along with as well as other side effects. Consuming large amounts of coffee might also cause headache, anxiety, agitation, ringing in the ears, along with as well as irregular heartbeats.

\section{Special precautions along with as well as} warnings

\section{Pregnancy along with as well as breast- feeding}

There is not enough reliable information about the safety of taking green coffee if you are pregnant or breast feeding. Stay on the safe side along with as well as avoid use.

\section{Abnormally high levels of homocysteine}

Consuming a high dose of chlorogenic acid for a short duration has caused increased plasma homocysteine levels, which may be associated with conditions such as heart disease.

\section{Anxiety disorders}

The caffeine in green coffee might make anxiety worse.

\section{Bleeding disorders}

There is some concern that the caffeine in green coffee might make bleeding disorders worse. 


\section{Diabetes}

Some research suggests that caffeine contained in green coffee might change the way people with diabetes process sugar.

Caffeine has been reported to cause increases as well as decreases in blood sugar. Use caffeine with caution if you have diabetes along with as well as monitor your blood sugar carefully.

\section{Diarrhea}

Green coffee contains caffeine. The caffeine in coffee, especially when taken in large amounts, can worsen diarrhea.

\section{Glaucoma}

Taking caffeine which is contained in green coffee can increases pressure inside the eye. The increase starts within 30 minutes and lasts for at least 90 minutes.

\section{High blood pressure}

Taking caffeine found in green coffee might increase blood pressure in people with high blood pressure. However, this effect might be less in people who consume caffeine from coffee or other sources regularly.

\section{High cholesterol}

Certain components of unfiltered coffee have been shown to increase cholesterol levels. These components can be found in green coffee as well. However, it is unclear if green coffee can also cause increased cholesterol levels.

\section{Irritable bowel syndrome (IBS)}

Green coffee contains caffeine. The caffeine in coffee, especially when taken in large amounts, can worsen diarrhea along with as well as might worsen symptoms of IBS.

\section{Thinning bones (osteoporosis)}

Caffeine from green coffee along with as well as other sources can increase the amount of calcium that is flushed out in the urine. This might weaken bones. If you have osteoporosis, limit caffeine consumption to less than $300 \mathrm{mg}$ per day (approximately 2-3 cups of regular coffee). Taking calcium supplements may help to make up for calcium that is lost. Postmenopausal women, who have an inherited condition that keeps them from processing vitamin D normally, should be especially cautious when using caffeine.

\section{Green coffee or green tea: which is better for weight loss?}

It is supposed that no magic pill or powder can replace consistent work in the gym along with as well as a clean diet to lose fat. There are a handful of ingredients that may help boost the metabolism along with as well as enhance the weight-loss efforts. Your morning cup of Green Coffee or Green Tea may actually help your weight loss efforts. But when it comes to weight loss, which one is to be preferred from these two Green Coffee or Green Tea?

Green tea has carved a niche for itself in the fitness world. It seems to have got most of the limelight as far as weight loss is concerned.

It has antioxidant along with as well as antiinflammatory properties, which make it quiet attractive! However, in the recent years another beverage has attracted much attention as a healthy weight loss enhancing beverage along with as well as the beverage is green coffee. It is believed to be really effective in treating heart diseases along with as well as diabetes along with causing weight loss.

These two ingredients - Green Coffee or Green Tea - may already be a part of your daily morning routine, but they're also sold in 
supplement form as green tea along with as well as green coffee extract.

\section{What green coffee does?}

According to studies consuming green coffee everyday can help the body in losing lots of weight in a period of 12 weeks. Green coffee works as a catalyst in the oxidation of fat.

It helps the release of fatty acids.

It improves metabolism.

It stimulates the absorption of fat in the liver.

\section{Green tea}

\section{What is it?}

Green tea is made from the leaves, stem along with as well as bud of the plant 'Camellia sinensis'. It is most often taken as a beverage but is also available in the form of a supplement. It isn't fermented like many tea, it is instead made by steaming fresh leaves at high temperatures.

The steaming process enhances the polyphenols in it. Polyphenols present in green tea help in preventing inflammation along with as well as swelling in the body.

It also has $2-4 \%$ of caffeine that makes it effective in boosting metabolism along with as well as stimulating the nervous system, heart along with as well as muscles by the release of neurotransmitters.

\section{What it does}

Studies say that green tea effectively prevents breast cancer, colon cancer, diabetes, heart disease along with as well as leukemia.

It is high in antioxidants along with as well as help in preventing the premature aging of skin.
It is rich in the antioxidant polyphenol, which breaks down the fat along with as well as increases energy in the body.

It improves mental clarity along with as well as alertness.

Lowers blood pressure.

\section{Green coffee or green tea?}

Both green coffee along with as well as green tea has some exceptional health benefits. They improve overall health, help burn fat along with as well as protect from ageing. However, based on recent studies, while talking about weight loss, green coffee is a lot more effective_as weight loss results appear faster. It helps people lose weight without crash diets along with as well as heavy workouts.

The amount of research along with as well as analysis done on green tea along with as well as the health benefits it has on an individual is slightly more than the limited studies done so far on Green coffee beans, but on the other hand, the evidence for weight loss with green coffee beans extracts is slightly higher than green tea.

Green tea offers a number of health benefits but its effects are seen much slower than the impact green coffee bean extracts has on an individual.

Green Coffee or Green Tea naturally contains caffeine along with as well as hence large amounts of green tea supplements or beverage can cause a number of side effects such as anaemia, anxiety disorders, heartburn, convulsions along with as well as headaches. On the other hand green coffee bean extracts are prepared from decaffeinated coffee beans along with as well as only contain chlorogenic acid, which is the main component for overall health as well as weight loss. 


\section{Lemon}

The lemon, Citrus limon (L.) Osbeck, is a species of small evergreen tree in the flowering plant family Rutaceae, native to South Asia, primarily North eastern India.

The tree's ellipsoidal yellow fruit is used for culinary along with as well as non-culinary purposes throughout the world, primarily for its juice, which has both culinary along with as well as cleaning uses. ${ }^{[2]}$ The pulp along with as well as rind (zest) are also used in cooking along with as well as baking. The juice of the lemon is about $5 \%$ to $6 \%$ citric acid, with a $\mathrm{pH}$ of around 2.2, giving it a sour taste. The distinctive sour taste of lemon juice makes it a key ingredient in drinks along with as well as foods such as lemonade along with as well as lemon meringue pie. Lemon juice, rind, along with as well as peel is used in a wide variety of foods along with as well as drinks. The whole lemon is used to make marmalade, lemon curd along with as well as lemon liqueur. Lemon slices along with as well as lemon rind are used as a garnish for food along with as well as drinks. Lemon zest, the grated outer rind of the fruit, is used to add flavour to baked goods, puddings, rice, along with as well as other dishes.

\section{Juice}

Lemon juice is used to make lemonade, soft drinks, along with as well as cocktails. It is used in marinades for fish, where its acid neutralizes amines in fish by converting them into non-volatile ammonium salts, along with as well as meat, where the acid partially hydrolyzes tough collagen fibbers, tenderizing the meat, but the low $\mathrm{pH}$ denatures the proteins, causing them to dry out when cooked. Lemon juice is frequently used in the United Kingdom to add to pancakes, especially on Shrove Tuesday. Lemon juice is also used as a short-term preservative on certain foods that tend to oxidize along with as well as turn brown after being sliced (enzymatic browning), such as apples, bananas, along with as well as avocados, where its acid denatures the enzymes.

\section{Peel}

In Morocco, lemons are preserved in jars or barrels of salt. The salt penetrates the peel along with as well as rind, softening them, along with as well as curing them so that they last almost indefinitely. The preserved lemon is used in a wide variety of dishes. Preserved lemons can also be found in Sicilian, Italian, Greek, along with as well as French dishes.

\section{Side effects of lemon water}

Lemon water is generally safe to drink, but there are a few potential side effects to be aware of. Lemon contains citric acid, which may erode tooth enamel (an ironic twist for people using lemon to help bad breath). To limit the risk, drink lemon water through a straw, along with as well as rinse your mouth afterwards. When it comes to heartburn, lemon water can go either way. The acidic citric acid may stimulate heartburn in some people. Others may experience relief from heartburn since lemons become alkaline in the digestive tract. If lemons aggravate your heartburn, avoid drinking lemon water. Some people report more frequent trips to the bathroom when drinking lemon water. Although lemon juice is often referred to as a diuretic, a substance that increases urine production, evidence doesn't show that vitamin $\mathrm{C}$ from natural sources like lemons has diuretic effects.

\section{Health benefits of lemon water}

It promotes hydration. According to the Food along with as well as Nutrition Board, the dietary reference intake for water is 91 to 125 ounces. 
It's a good source of vitamin C.

It improves your skin quality.

It supports weight loss.

It aids digestion.

It freshens breath.

It helps prevent kidney stones.

\section{Pine apple}

The pineapple (Ananascomosus) is a tropical plant with an edible multiple fruit consisting of coalesced berries, also called pineapples, along with as well as the most economically significant plant in the family Bromeliaceae. Pineapples may be cultivated from the offset produced at the top of the fruit, possibly flowering in five to ten months along with as well as fruiting in the following six months. Pineapples do not ripen significantly after harvest. In 2016, Costa Rica, Brazil, along with as well as the Philippines accounted for nearly one-third of the world's production of pineapples.

In a 100-gram reference amount, raw pineapple is a rich source of manganese (44\% Daily Value, DV) along with as well as vitamin C (58\% DV), but otherwise contains no essential nutrients in significant quantities (Table 1-3).

\section{Pineapple: Health benefits, risks \& nutrition facts}

Serving size: 1 cup chunks (165 g).

Immune system support.

Bone strength.

Eye health.
"Pineapples can help reduce the risk of macular degeneration, a disease that affects the eyes as people age, due in part to its high amount of vitamin $\mathrm{C}$ along with as well as the antioxidants it contains," Flores said.

Digestion.

Anti-Inflammatory benefits.

\section{Material and Methods}

Green coffee beans(Hot and cold D. $\left.\mathrm{H}_{2} \mathrm{O}\right)=2 \mathrm{gm}$ in $10 \mathrm{ml} \mathrm{D} \cdot \mathrm{H}_{2} \mathrm{O}$

Green Tea $\left(\mathrm{Hot}\right.$ and cold D. $\left.\mathrm{H}_{2} \mathrm{O}\right)=2 \mathrm{gm}$ in $10 \mathrm{ml}$ D. $\mathrm{H}_{2} \mathrm{O}$

Lemon $\left(\mathrm{Hot}\right.$ and cold D. $\left.\mathrm{H}_{2} \mathrm{O}\right)=2 \mathrm{gm}$ in $10 \mathrm{ml}$ D. $\mathrm{H}_{2} \mathrm{O}$

Pine apple (Hot and cold D. $\left.\mathrm{H}_{2} \mathrm{O}\right)=2 \mathrm{gm}$ in 10 $\mathrm{ml} \mathrm{D.} \mathrm{H}_{2} \mathrm{O}$

\section{Process:-1}

\section{Antimicrobial test}

Firstly we take an extract of (pine apple, lemon, green coffee beans, normal coffee, green tea\& normal tea) for the comparison between Normal coffee/tea to green coffee/tea. According to the calculations we take $2 \mathrm{gm}$ of

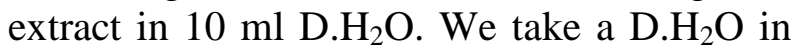
two categories such as Hot water along with as well as cold water for the exact evolution of the antimicrobial test. Then we take a $2 \mathrm{gm}$ of each along with as well as everyone extract which are given for the antimicrobial test, mixed with the Hot along with as well as Cold

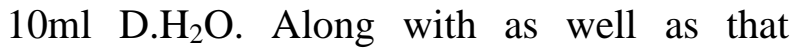
extract leave for overnight. After that, make L.B medium plates for the testing of the Antimicrobial test. Then we evaluated the antimicrobial test for the Disk Diffusion Method. 
Disk diffusion method where firstly put the disk on medium and for the evaluation of Antimicrobial test. We take a bacterium (E.coli) along with as well as that bacteria sample is spread over the petriplate along with as well as disk are putted on the petriplates along with as well as after that extract sample are put over the disk. And leave for overnight.

For the perfect evolution ZONE OF INHIBITION are shown in our plates which means that particular extract fight against a particular bacteria.

\section{Material required}

$0.1 \mathrm{ml}$ extract of(Normal\& Hot water) green tea+0.5 ml D. $\mathrm{H}_{2} \mathrm{O}$

$0.1 \mathrm{ml}$ extract of (Normal \& Hot water) green coffee beans $+0.5 \mathrm{ml} \mathrm{D.} \mathrm{H}_{2} \mathrm{O}$

$0.1 \mathrm{ml}$ extract of (Normal \& Hot water) normal tea+0.5ml D. $\mathrm{H}_{2} \mathrm{O}$

$0.1 \mathrm{ml}$ extract of (Normal \& Hot water) normal coffee+0.5ml D. $\mathrm{H}_{2} \mathrm{O}$

$0.1 \mathrm{ml}$ extract of (Normal \&Hot water) lemon peels $+0.5 \mathrm{ml} \mathrm{D.} \mathrm{H}_{2} \mathrm{O}$

$0.1 \mathrm{ml}$ extract of (Normal \&Hot water) pineapple+0.5ml D. $\mathrm{H}_{2} \mathrm{O}$

24ml methanol +0.0009463molar DPPH (2,2Di Phenyl 1-1-Picryl hydrazyl)

After taking a $01 \mathrm{ml}$ extract in other test tube and mixed with $0.5 \mathrm{ml} \mathrm{D.} \mathrm{H}_{2} \mathrm{O}$

(Methanol $24 \mathrm{ml}+$ DPPH 0.0009463molar)

\section{Process}

Firstly we take a $2 \mathrm{gm}$ extract of Green tea/Normal tea, Green coffee beans/Normal coffee, lemon, pine apple of Hot along with as well as Normal $10 \mathrm{ml} \mathrm{D.} \mathrm{H}_{2} \mathrm{O}$.

Then in these extract we take $0.1 \mathrm{ml}$ of extract transfer to another test tube.

After Then make a $24 \mathrm{ml}$ of methanol solution along with as well as mixed with the 0.0009463 molar DPPH mixture in a conical flask.

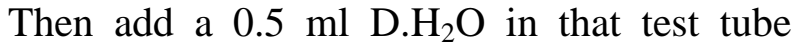
which is accurate measure of extract.

Then transfer a $0.1 \mathrm{ml}$ conical flask solution (methanol+ DPPH) in each extract simultaneously. The mixture were shaken gently \& allowed to stand at room temperature for 30 minutes. After few minutes we take a O.D at $517 \mathrm{~nm}$ of each extract. \& calculate DPPH scavenging effect by DPPH scavenging effect $\left.(\%)=\left\{\left(\mathrm{A}_{0}-\mathrm{A}\right) / \mathrm{A}_{0}\right)\right\} \times 100$

Where,

$\mathrm{A}_{\mathrm{O}}=\mathrm{absorbance}$ of control reaction

A=absorbance in present of each and every one the extract sample $\&$ references

*O.D at 517nm (methanol+ DPPH) with respects to $\mathrm{D} \cdot \mathrm{H}_{2} \mathrm{O}=0.444 \mathrm{~nm}$

\section{Result and Discussion}

The disk diffusion test, or agar diffusion test, or Kirby-Bauer test (disc-diffusion antibiotic susceptibility test, disc-diffusion antibiotic sensitivity test, $\mathrm{KB}$ test), is a test of the antibiotic sensitivity of bacteria. It uses antibiotic discs to test the extent to which bacteria are affected by those antibiotics. In this test, wafers containing antibiotics are placed on an agar plate where bacteria have been placed, along with as well as the plate is left to incubate. If an antibiotic stops the 
bacteria from growing or kills the bacteria, there will be an area around the wafer where the bacteria have not grown enough to be visible. This is called a zone of inhibition. The size of this zone depends on many factors, one being how effective the antibiotic is at stopping the growth of the bacterium. Another factor that will influence the size of a zone is the diffusion of the antibiotic within the agar medium along with as well as varies based on the molecular configuration of the antibiotic. Once the zone diameter is measured it must be compared to a database of zone standards to determine if the bacterium being studied is susceptible, moderately susceptible or resistant to the antibiotic in question. A pure bacterial culture is suspended in buffer, standardized to turbidity along with as well as swabbed uniformly across a culture plate. A filter-paper disk, impregnated with the compound to be tested, is then placed on the surface of the agar. The compound diffuses from the filter paper into the agar. The concentration of the compound will be highest next to the disk, along with as well as will decrease as distance from the disk increases. If the compound is effective against bacteria at a certain concentration, no colonies will grow where the concentration in the agar is greater than or equal to the effective concentration. This is the zone of inhibition. This along with the rate of antibiotic diffusion is used to estimate the bacteria's susceptibility to that particular antibiotic. In general, larger zones correlate with smaller minimum inhibitory concentration (MIC) of antibiotic for those bacteria. Inhibition produced by the test is compared with that produced by known concentration of a reference compound. This information can be used to choose appropriate antibiotics to combat a particular infection.

\section{Diphenyl-1-picrylhydrazyl (DPPH) assay}

The antioxidant activity of the extracts was determined using the DPPH free radical scavenging assay with some modifications. Briefly, the universal bottle was contained 50 $\mu \mathrm{L}$ of $L$. camara extracts in concentrations from 1 to $5 \mathrm{mg} / \mathrm{mL}$ and $5 \mathrm{~mL} 0.004 \%(\mathrm{w} / \mathrm{v})$ solution of DPPH was added. The obtained mixture was vortexed, incubated for $30 \mathrm{~min}$ in room temperature in a relatively dark place along with as well as then was read using spectrophotometer at $517 \mathrm{~nm}$. The blank was $80 \%(\mathrm{v} / \mathrm{v})$ methanol. Ascorbic acid (Vitamin C) was used for comparison. Measurements were taken in triplicate. DPPH scavenging effect was calculated using the following equation:

$\mathrm{DPPH}$ scavenging effect $(\%)=\left\{\left(\mathrm{A}_{0^{-}}\right.\right.$ A)/A $\left.\left.A_{0}\right)\right\} \times 100$

Where $\mathrm{A} 0$ is the absorbance of negative control (0.004\% DPPH solution) and $\mathrm{A}$ is the absorbance in presence of extract. The results were reported as $\mathrm{IC}_{50}$ values along with as well as ascorbic acid equivalents (AAE, mg/g) of $L$. camara extracts. Antioxidant test define against the oxidation reaction, it is beneficial for a human body. Antioxidants are tremendously important substances which possess the ability to protect the body from damage caused by free radical induced oxidative stress. The antioxidant potential of $L$ methanol extracts was investigated in the search for new bioactive compounds from natural resources. It became clear that leaves, flower, root along with as well as stem present the highest antioxidant activity compared with reference antioxidant Vitamin $\mathrm{C}$ for DPPH scavenging activity.

Polyphenols was found in each and every one the samples and in the following order: Leaves $>$ flower $>$ root $>$ stem $>$ fruits. The obtained results for DPPH are in agreement with the phenol contents determined for each sample. Plant polyphenols act as reducing agents along with as well as antioxidants by the hydrogendonating property of their hydroxyl groups (Fig. 1-6). 
Table.1

\begin{tabular}{|c|c|c|}
\hline Contents & GRECOBE- The Green Coffee & Green Tea \\
\hline $\begin{array}{l}\text { Chlorogenic } \\
\text { Acids }\end{array}$ & $\begin{array}{l}\text { Grecobe- more than } 45 \% \\
\text { Other Brands- } 3-5 \%\end{array}$ & Nil \\
\hline 5-CQA & $\begin{array}{l}\text { Grecobe- more than } 20 \% \\
\text { Other Brands- } 1-2 \%\end{array}$ & Nil \\
\hline Caffeine & Decaffeinated & Approx. $30-40 \mathrm{mg} /$ cup \\
\hline Taste & Mild & Strong \& Bitter \\
\hline Packing & Ready to use with warm water & Need to boil \\
\hline $\begin{array}{l}\text { Weight Loss } \\
\text { properties }\end{array}$ & $\begin{array}{l}\text { weight loss results appear faster as the clinical } \\
\text { data available }\end{array}$ & Known for weight loss with less clinical data \\
\hline Immunity & $\begin{array}{l}\text { One of the Strongest antioxidant as the clinical } \\
\text { data available }\end{array}$ & No Clinical study available \\
\hline
\end{tabular}

Table.2

\begin{tabular}{|c|c|}
\hline Extract & O.D \\
\hline Normal coffee(Hot water) & 0.366 \\
\hline Normal coffee(Normal water) & 0.42 \\
\hline Normal tea(Hot water) & 0.305 \\
\hline Normal tea(normal water) & 0.306 \\
\hline Lemon(Hot water) & 0.413 \\
\hline Lemon(Normal water) & 0.356 \\
\hline Pine apple(Hot water) & 0.308 \\
\hline Pine apple(Normal water) & 0.348 \\
\hline Green Beans(Hot water) & 0.288 \\
\hline Green Beans(Normal water) & 0.295 \\
\hline Green tea(Hot water) & 0.286 \\
\hline Green tea(Normal water) & 0.325 \\
\hline
\end{tabular}


Table.3

\begin{tabular}{|c|c|}
\hline Extract & DPPH scavenging effect \\
\hline Normal coffee(Hot water) & 17.56 \\
\hline Normal coffee(Normal water) & 5.405 \\
\hline Normal tea(Hot water) & 31.30 \\
\hline Normal tea(normal water) & 31.08 \\
\hline Lemon(Hot water) & 6.981 \\
\hline Lemon(Normal water) & 19.81 \\
\hline Pine apple(Hot water) & 30.630 \\
\hline Pine apple(Normal water) & 21.62 \\
\hline Green Beans(Hot water) & 35.135 \\
\hline Green Beans(Normal water) & 33.55 \\
\hline Green tea(Hot water) & 35.58 \\
\hline Green tea(Normal water) & 26.80 \\
\hline
\end{tabular}

Fig.1

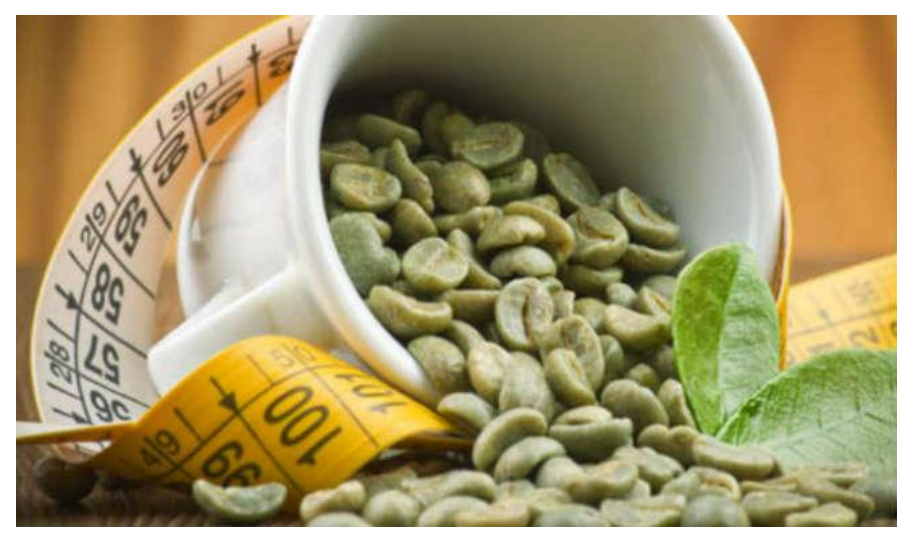

Fig.2
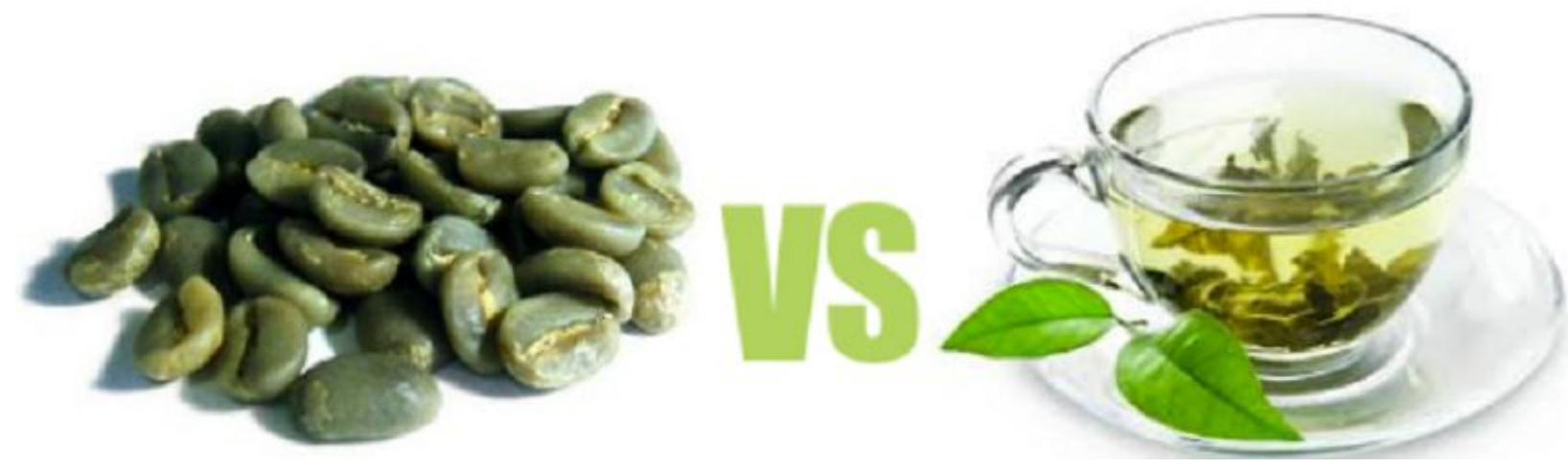
Fig.3

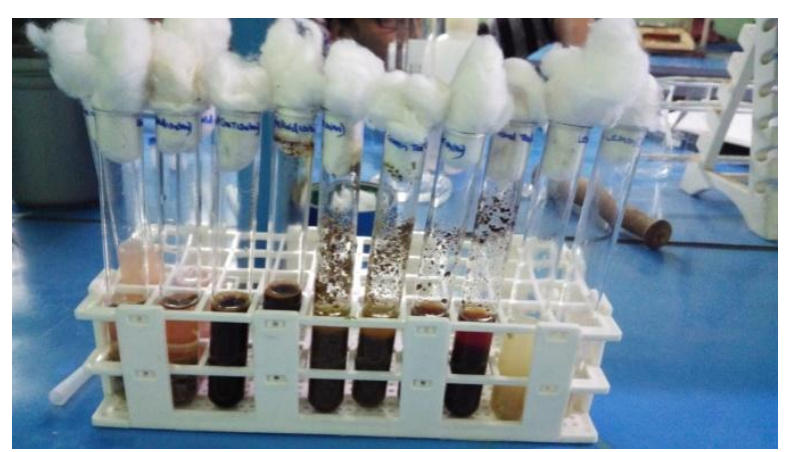

Fig.4

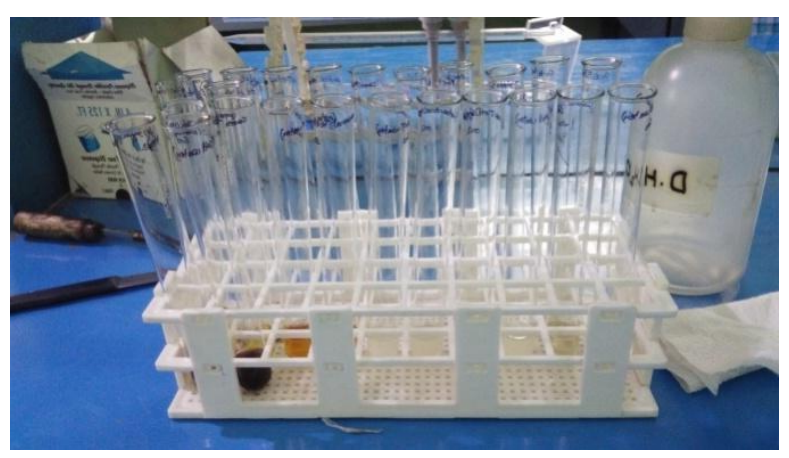

Fig.5

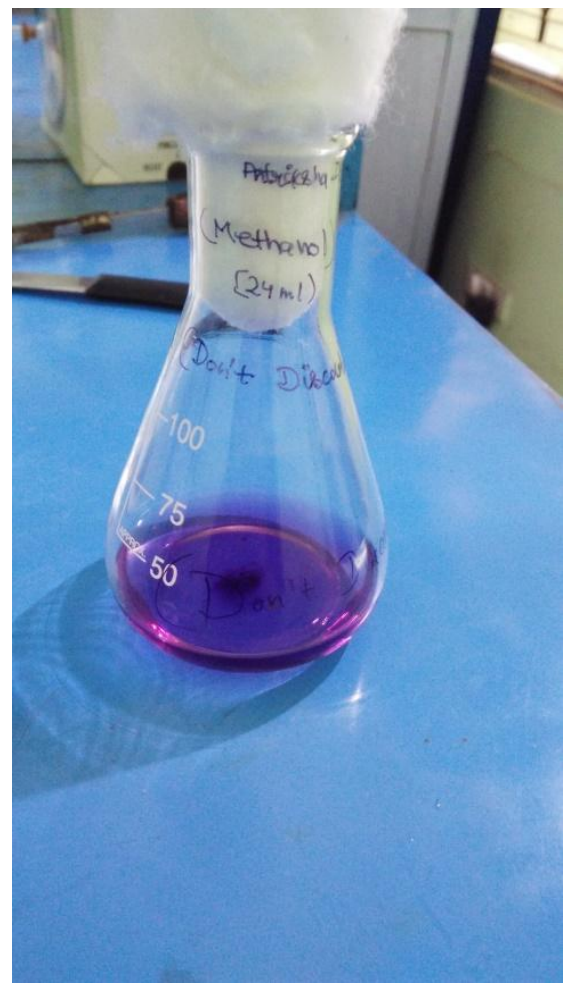


Fig.6

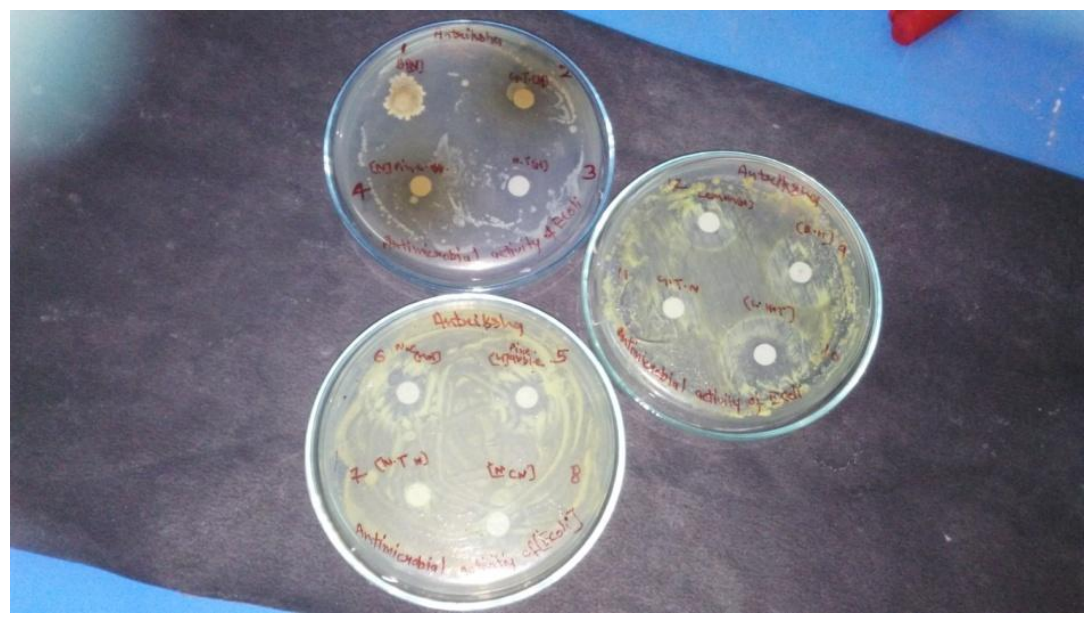

Hence, we could conclude that these polyphenols are responsible for the observed antioxidant activity in this study. An antioxidant is a molecule that inhibits the oxidation of other molecules. Oxidation is a chemical reaction that can produce free radicals, leading to chain reactions that may damage cells.

Antioxidants such as thiols or ascorbic acid (vitamin C) terminate these chain reactions. The results showed that each and every one the plant parts possessed antioxidant properties including radical scavenging, xanthine oxidase inhibition along with as well as nitrites scavenging activities. The antioxidative activities were correlated with the total phenol. The leaves extract was more effective than that of other parts.

This study about "A comparative analysis of Antimicrobial \& Antioxidant Activity between Green Tea, Green Coffee, Pine Apple \& Lemon Juice suggests that extracts exhibit great potential for antioxidant activity along with as well as may be useful for their nutritional along with as well as medicinal functions. In this research the antimicrobial along with as well as antioxidant activity of green tea was higher than green coffee, normal tea, normal coffee, along with as well as pine apple along with as well as lemon juice.

\section{Acknowledgement}

Author would like to thank to Dr. Satyam Khanna (Director of RASS Biosolution Pvt. Ltd. Kanpur, U.P.), Dr Vinay Dwivedi (HOD) \& Srinath Pandey (Department of Biotechnology, NVPEMI, Panki, Kanpur, U.P.), Dr. Prashant Ankur Jain (Assistant Professor, Department of Computational Biology and Bioinformatics, JIBB, SHUATS, Allahabad, U.P.) and Dr Ved Kumar Mishra (Director, Vidhyashram Educational and Development Hub (VED Hub), (SHACT), Varanasi, U.P.) for supporting this work by providing a good research environment and related facilities.

\section{References}

Abdul G Dulloo, Claudette Duret, Dorothée Rohrer, Lucien Girardier, Nouri Mensi, Marc Fathi, Philippe Chantre, and Jacques Vandermander (1999) "Efficacy of a green tea extract rich in catechin polyphenols and caffeine in increasing 24-h energy expenditure and fat oxidation in humans", Am J Clin Nutr 1999; 70: 1040-5. Printed in 
USA. () 1999 American Society for Clinical Nutrition

Balentine DA, Wiseman SA, Bouwens LC. The chemistry of tea flavonoids. Crit Rev Food Sci Nutr 1997; 37:693-704.

Bracco D, Ferrarra JM, Arnaud MJ, Jéquier E, Schutz Y. Effects of caffeine on energy metabolism, heart rate, and methylxanthine metabolism in lean and obese women. Am J Physiol 1995;269:E671-8.

Brand-Williams, W., M. E. Cuvelier and C. Berset, (1995), "Use of a free radical method to evaluate antioxidant activity" Lebensm.-Wiss. u.-Technol., 28.25-30 (1995)

Chow HH, Cai Y, Hakim IA, et al., Pharmacokinetics and safety of green tea polyphenols after multiple-dose administration of epigallocatechin gallate and polyphenon $\mathrm{E}$ in healthy individuals. Clin Cancer Res 2003; 9:3312-9.

Dulloo AG, Seydoux J, Girardier L, Chantra $\mathrm{P}$, Vandermander J. Green tea and thermogenesis: interactions between catechinpolyphenols, caffeine and sympathetic activity. Int J Obes Relat Metab Disord (in press).

Frei B, Higdon JV. Antioxidant activity of tea polyphenols in vivo: evidence from animal studies. J Nutr 2003; 133: $3275 \mathrm{~S}-84 \mathrm{~S}$.

Henning SM, Fajardo-Lira C, Lee HW, Youssefian AA, Go VLW, Heber D. Catechin content of 18 teas and a green tea extract supplement correlated with the antioxidant capacity. Nutr Cancer 2003; 45: $226-35$.

Hodgson JM, Croft KD, Mori TA, Burke V, Beilin LJ, Puddey IB. Regular ingestion of tea does not inhibit in vivo lipid peroxidation in humans. J Nutr 2002; 132: 55-8.

Hollman PCH, Tijburg LBM, Yang CS. Bioavailability of flavonoids from tea.
Crit Rev Food Sci Nutr 1997; 37: 71938.

Khokhar S, Magnusdottir SG. Total phenol, catechin, and caffeine contents of teas commonly consumed in the United Kingdom. J Agric Food Chem 2002; 50: 565-70.

Kondo K, Kurihara M, Miyata N, Suzuki T, Toyoda M. Scavenging mechanisms of ()-epigallocatechin gallate and ()epicatechin gallate on peroxyl radicals and formation of superoxide during the inhibitory action. Free Radic Biol Med 1999; 27:855- 63.

Lambert JD, Yang CS. Mechanisms of cancer prevention by tea constituents. J Nutr 2003; 133: 3262S-7S.

Lee MJ, Maliakal P, Chen L, et al., Pharmacokinetics of tea catechins after ingestion of green tea and ()epigallocatechin-3-gallate by humans: formation of different metabolites and individual variability. Cancer Epidemiol Biomarkers Prev 2002; 11: 1025-32.

Lee MJ, Prabhu S, Meng X, Li C, Yang CS. An improved method for the determination of green and black tea polyphenols in biomatrices by highperformance liquid chromatography with coulometric array detection. Anal Biochem 2000; 279:164 -9.

Lee MJ, Wang ZY, Li H, et al., Analysis of plasma and urinary tea polyphenols in human subjects. Cancer Epidemiol Biomarkers Prev 1995; 44: 393-9.

Miller NJ, Sampson J, Candeias LP, Bramley PM, Rice-Evans CA. Antioxidant activities of carotenes and xanthophylls. FEBS Lett 1996; 384: $240-2$.

Rietveld A, Wiseman S. Antioxidant effects oftea: evidence from human clinical trials. J Nutr 2003;133:3285S-92S.

Stagg GV, Millin DJ. The nutritional and therapeutic value of tea- a review. $J$ 
Sci Food Agric 1975;26:1439-59.

Susanne M Henning, Yantao Niu, Nicolas H Lee, Gail D Thames, Rosario R Minutti, Hejing Wang, Vay Liang W Go, and David Heber, (2004), "Bioavailability and antioxidant activity of tea flavanols after consumption of green tea, black tea, or a green tea extract supplement" Am J Clin Nutr 2004;80:1558 - 64. Printed in USA. (C) 2004 American Society for Clinical Nutrition

Tomonori Nagao, Tadashi Hase, and Ichiro Tokimitsu, (2007), “A Green Tea Extract High in Catechins Reduces
Body Fat and Cardiovascular Risks in Humans", Obesity. 2007; 15:14731483.

Warden BA, Smith LS, Beecher GR, Balentine DA, Clevidence BA. Catechins are bioavailable in men and women drinking black tea throughout the day. J Nutr 2001; 131: 1731-7.

Yang CS, Chung JY, Yang G, Chhabra SK, Lee MJ. Tea and tea polyphenols in cancer prevention. J Nutr 2000; 130: 472S-8S.

Yang CS, Maliakal P, Meng X. Inhibition of carcinogenesis by tea. Annu Rev Pharmacol Toxicol 2002; 42: 25-54.

\section{How to cite this article:}

Jagriti Singh, Satyam Khanna, Vinay Dwivedi, Srinath Pandey, Prashant Ankur Jain and Ved Kumar Mishra. 2019. A Comparative Analysis of Antimicrobial and Antioxidant Activity Between Green Tea, Green Coffee, Pine Apple and Lemon Juice. Int.J.Curr.Microbiol.App.Sci. 8(11): 1531-1545. doi: https://doi.org/10.20546/ijcmas.2019.811.178 